\title{
INSULIN-LIKE GROWTH FACTOR I SENSITIZATION
}

\section{REJUVENATES SLEEP PATTERNS IN OLD MICE}

J.A. Zegarra-Valdivia ${ }^{1,2,3,4}$, J. Fernandes ${ }^{1,5}$, A. Trueba-Saiz ${ }^{1,2}$, M.E. Fernandez de Sevilla $^{1,2}$, J. Pignatelli ${ }^{1,2}$, K. Suda ${ }^{1,6}$, L. Martinez-Rachadell ${ }^{1,2}$, A.M. Fernandez ${ }^{1,2}$, J. Esparza ${ }^{1}$, M. Vega ${ }^{7}$, A. Nuñez ${ }^{8}$, I. Torres Aleman ${ }^{1,2,4}$

${ }^{1}$ Cajal Institute (CSIC), Madrid, Spain. ${ }^{2}$ CIBERNED, Spain. ${ }^{3}$ Universidad Nacional de San Agustín de Arequipa, Perú. ${ }^{4}$ Achucarro Basque Center for Neuroscience, Leioa, Spain. ${ }^{5}$ Universidade Federal São Paulo, São Paulo, Brazil, ${ }^{5}$ Division of Diabetes and Endocrinology, Kobe University Graduate School of Medicine, Kobe, Japan,

${ }^{6}$ Allinky Biopharma, Madrid, Spain. ${ }^{7}$ Dept Neurosciences, School of Medicine, UAM, Madrid. Spain

Keywords: Aging, IGF-I, orexinergic neurons, sleep. 


\begin{abstract}
Sleep disturbances are common during aging. Compared to young animals, old mice show altered sleep structure, with changes in both slow and fast electrocorticographic (ECoG) activity and fewer transitions between sleep and wake stages. Insulin-like growth factor I (IGF-I), which is involved in adaptive changes during aging, was previously shown to increase ECoG activity in young mice and monkeys. Furthermore, IGF-I shapes sleep architecture by modulating the activity of mouse orexin neurons in the lateral hypothalamus (LH). We now report that both ECoG stimulation and activation of orexin neurons by systemic IGF-I is abrogated in old mice. Moreover, stimulation of orthodromically activated LH neurons by either systemic or local IGF-I in young mice is absent in old mice. As orexin neurons of old mice show markedly increased IGF-I receptor (IGF-IR) levels, suggesting loss of sensitivity to IGF-I, we treated old mice with AIK3a305, a novel IGF-IR sensitizer, and observed restored responses to IGF-I and rejuvenation of sleep patterns. Thus, disturbed sleep structure in aging mice may be related to impaired IGF-I signaling onto orexin neurons, reflecting a broader loss of IGF-I activity in the aged mouse brain.
\end{abstract}




\section{Introduction}

Sleep disturbances are so common during aging that whether they are an inherent component of the aging process is under debate ${ }^{1}$. Importantly, sleep alterations present together with metabolic and cognitive impairments frequently found in aged individuals, but their contribution to pathology is unclear ${ }^{2,3}$. Therefore, knowledge of the mechanisms underlying these age-associated changes in sleep architecture is of great interest.

We recently documented that circulating IGF-I, a hormone that participates in the aging process all along phylogeny ${ }^{4}$, is also involved in the sleep/wake circadian cycle, as mice with reduced serum IGF-I present altered circadian electrocorticographic (ECoG) activity, among many other disturbances ${ }^{5}$. Moreover, IGF-I directly shapes sleep architecture by modulating the activity of hypothalamic orexin neurons ${ }^{6}$, a group of neurons in the lateral hypothalamus (LH) involved in sleep regulation ${ }^{7}$.

Significantly, aging is associated with reduced serum IGF-I levels in all mammalian species studied ${ }^{8}$. However, whether IGF-I plays a detrimental or protective role in the

aging brain is under debate ${ }^{9,10}$. At any rate, loss of IGF-I activity in the aging brain has been previously documented by us ${ }^{11}$ and many others ${ }^{12-14}$. We hypothesized that orexin neurons in the aged brain might also lose sensitivity to this hormone, which, coupled with age-associated reduction of serum IGF-I would aggravate IGF-I loss-offunction, and eventually affect sleep/wake patterns.

We observed that systemic injection of IGF-I to old mice resulted in reduced c-fos expression in orexin neurons compared to young mice. Also, the responses of LH neurons to either systemic or local IGF-I were abrogated in old mice, which also points to loss of sensitivity to this growth factor. Since orexin neurons in old mice express higher IGF-IR levels, suggesting a compensatory mechanism to cope with lower brain IGF-I activity, we treated old mice with an IGF-IR sensitizer and found that responses to IGF-I recovered and sleep patterns rejuvenated. Thus, reduced IGF-I input to orexin neurons during aging contributes to age-associated sleep disturbances.

\section{Results}

\section{Changes in sleep architecture in old mice}

We first confirmed that changes in sleep structure during normal aging documented in humans ${ }^{15}$ are also present in aged mice ${ }^{16}$. Using ECoG recordings during the light period (corresponding to the inactive phase in mice, Figure 1A), we observed that old 
mice ( $>18$ months old) have markedly different patterns of ECoG activity in both slow and high-frequency bands, as compared to young ones ( $<6$ months old). Thus, the typical age-related decrease in $\delta$ activity ${ }^{15}$, together with increases in $\theta, \alpha$, and $\beta$ bands were observed (Figure 1B-E). The $\gamma$ band was significantly depressed, specifically at Zeitgeber time (ZT) 19, suggesting that young animals woke up while old ones stayed sleeping (Figure 1F). ECoG analysis during the inactive phase shows a total mean decrease of $\delta$ activity (Figure $1 \mathrm{G}$ ).

Next, we analyzed sleep onset latency and found that old mice show a significantly shorter latency to sleep (Figure 1H). We combined both sexes for these experiments, as ECoG patterns were similar in males and females (Suppl Figure 1A, B).

\section{Old mice show reduced sensibility to IGF-I}

We previously reported that systemic administration of IGF-I ( $1 \mu \mathrm{g} / \mathrm{g}$, ip) to young mice results in enhanced ECoG activity ${ }^{17}$. ECoG responses to IGF-I induced a decrease of $\delta$ waves, while faster frequencies were significantly enhanced (Figure $2 \mathrm{~A})$. In contrast, old mice showed a slight increase of faster frequencies after ip IGF-I injection, reaching statistical significance only in the $\beta$ frequency band (compare Figure $2 \mathrm{~A}, \mathrm{~B}$ with Figure 2 in ref 17).

Orexin neurons are a discrete cell population in the lateral hypothalamus that participate in sleep/wake regulation ${ }^{7,18}$. Since IGF-I shapes sleep architecture through them ${ }^{6}$, we speculated that these hypothalamic neurons might be involved in ageassociated sleep disturbances by losing sensitivity to IGF-I. After systemic IGF-I injection, young mice responded with increased c-fos expression in orexin neurons, Conversely, whereas old mice had significantly higher basal c-fos immunoreactivity in orexin neurons than young mice, they did not respond to IGF-I (Figure $2 \mathrm{C}-\mathrm{G}$ ).

To elucidate whether reduced responses to systemic IGF-I are due to locally altered IGF-I signaling or reduced entrance of IGF-I from the periphery ${ }^{19,20}$, we recorded responses to IGF-I in the PeF area of the lateral hypothalamus (LH) after either peripheral or local administration in both young and old mice. First, we activated LH neurons through the locus coeruleus (LC) as described before ${ }^{6}$, and then we administered IGF-I either ip or locally (Figure 3A). While orthodromic stimulation of LH neurons elicited comparable evoked potentials and similar latency in young and old mice (Suppl Fig 1 C, D), this was not the case for their responses to IGF-I. Either after local (Figure 3B) or systemic (ip) IGF-I administration (Figure 3C), LH neurons of old 
mice responded with slightly reduced activity, whereas young mice responded with increased activity.

\section{IGF-IR sensitization recovers orexin responses to IGF-I}

Altered responses to local administration of IGF-I suggests changes in orexin sensitivity to this growth factor. Thus, we examined IGF-IR expression in these neurons using double immunocytochemistry for orexin and IGF-IR (Figure 4A). Image analysis revealed a marked increase in double labelled IGF-IR/orexin cells in old mice (Figure 4B), while the number of orexin neurons (mean per field) was similar in both age groups (Figure 4C).

To confirm a loss of sensitivity to IGF-I in the old brain and at the same time assess a potential treatment for age-associated sleep disturbances, we treated aging mice with AIK3a305 (20 mg/kg/day; ip, 1 month), a novel IGF-IR sensitizer (Suppl Fig 2A) that crosses the blood-brain-barrier (Suppl Fig 2B) and found that c-fos responses to IGF-I were recovered to youthful levels (Figure 5A, B).

One month of treatment with AIK3a305 increased the percentage of $\delta$ waves during the inactive phase in old mice to levels seen in young animals (Figure 5C), while during the active phase, no differences were seen between groups (Suppl Fig 2C). The sleeponset latency was also recovered by AIK3a305 treatment (Figure 5D). Further, the sensibility of orthodromically stimulated LH neurons to local IGF-I injection was also recovered (Figure 5E). Orthodromic evoked potentials showed no significant differences under basal conditions between the three groups (Suppl Figure 2D).

\section{Discussion}

The present observations reinforce previous ones indicating that during aging, the brain loses sensitivity to IGF-I and suggest that this loss includes orexin neurons in the lateral hypothalamus. Since these neurons are involved in the sleep/wake cycle, and IGF-I influences sleep architecture through them ${ }^{6}$, we may conclude that sleep activity in old mice is disturbed at least in part because IGF-I input to orexin neurons is compromised. Indeed, the presence of higher IGF-IR levels in aging orexin neurons suggests a compensatory mechanism to impaired IGF-I signaling due to resistance, deficiency, or both ${ }^{21}$. This explanation is reinforced by the therapeutic actions of AIK3a305, a novel sensitizer of IGF-IR. The combined loss of sensitivity to IGF-I in orexin neurons and elsewhere, together with low serum IGF-I levels, will produce an 
overall reduction of IGF-I effects on the aged brain, as reflected by reduced ECoG responses to this growth factor.

Intriguingly, higher IGF-IR levels in the mouse brain have been associated with reduced longevity ${ }^{22}$. Although it may seem counterintuitive, higher IGF-IR levels may point to a less efficient IGF-I system in the brain, like this and previous ${ }^{23}$ observations suggest. Thus, higher expression of IGF-IR probably reflects post-receptor disturbances in IGF-I signal transmission ${ }^{24}$, resulting in reduced activation of the pathway. Since IGF-I downregulates the expression of its own receptor in the brain ${ }^{25}$, a rebound increased IGF-IR synthesis seems to take place. Other age-associated changes leading to aberrant IGF-IR function may also be involved, as reported for the brain insulin receptor 26.

The precise role of IGF-I in the aging process is controversial, albeit mainstream thinking supports the notion that its function, together with other members of the insulin family, is detrimental ${ }^{27-31}$. While many observations of the beneficial actions of IGF-I indicate that this notion is not univocal ${ }^{32-36}$, and is probably simplistic ${ }^{37,38}$, in the particular case of brain aging, the situation is even more confusing, with both detrimental $^{39,40}$ and beneficial actions of IGF-I ${ }^{41-45}$ profusely supported by data. Nevertheless, while these observations indicate that loss of IGF-I activity in the aging mouse brain disturbs sleep patterns, we cannot rule out potential beneficial effects of this loss in other aspects of brain function.

In summary, we observed a loss of sensitivity to IGF-I during brain aging, leading to dysregulated orexin function, which impacts on sleep patterns. Since IGF-IR sensitization recovered brain responses to IGF-I and rejuvenated sleep patterns, these results may provide new therapeutic avenues for age-related sleep disturbances.

\section{Material and Methods}

\section{Materials}

Antibodies used in this study include rabbit polyclonal anti-c-Fos (Abcam ab190289), rabbit polyclonal anti-IGF-I Receptor- $\beta$ (Santa Cruz 713/AC) and rabbit anti-IGF-I receptor $\beta$ XP (Cell Signaling Technology, USA), orexin polyclonal mouse antibody (Santa Cruz 80263), orexin polyclonal rabbit antibody (Abcam ab 6214), antiphosphoSer Akt (Cell Signaling, 9271S), and monoclonal anti-phosphotyrosine (clone PY20, BD Transduction Laboratories, USA). Human recombinant IGF-I was from PreProtech (USA). 


\section{Animals}

Adult female and male young (4-5 months) and old (12-22 months) C57BL/6J mice (28-34g, Harlan Laboratories, Spain) were used. The estrous cycle of the female mice was not determined. Experiments were done during the light phase, except when indicated. Animals were housed in standard cages $\left(48 \times 26 \mathrm{~cm}^{2}, 5\right.$ per cage $)$ and kept in a room with controlled temperature $\left(22^{\circ} \mathrm{C}\right)$ under a $12-12 \mathrm{~h}$ light-dark cycle. Mice were fed with a pellet rodent diet and water ad libitum. Animal procedures followed European guidelines (2010/63, European Council Directives) and were approved by the local Bioethics Committee (Government of the Community of Madrid, Proex 112/16).

\section{Drug administration}

IGF-I was dissolved in saline, and intraperitoneally (ip) injected $(1 \mu \mathrm{g} / \mathrm{g}$ body weight). In a subset of experiments, mice were processed for immunocytochemistry (see below) one or two hours after ip IGF-I injection to detect the expression of phospho-Akt or c-fos, respectively, whereas, in other experiments, PeF recordings were carried out immediately after ip injection. Alternatively, IGF-I was locally delivered in the PeF (10 $\mathrm{nM}$; $0.1 \mu \mathrm{l}$; coordinates from Bregma: A, -1.95; L, 1 and depth, 4.0 - 4.5mm), and injected animals were then submitted to electrophysiological recordings, as described below. Doses were selected based on previous work using pharmacological injections for both systemic and local/intraparenchymal administration. AIK3a305 (Allinky Biopharma, Spain) or the vehicle (DMSO in saline) were injected intraperitoneally (ip) at a dose of $20 \mathrm{mg} / \mathrm{kg} /$ day for one month.

\section{Electrophysiological recordings}

Mice were anesthetized with isofluorane ( $2 \%$ induction; $1-1.5 \%$ in oxygen, maintenance doses), placed in a David Kopf stereotaxic apparatus (Tujunga, CA, USA) in which surgical procedures and recordings were performed, with a warming pad (Gaymar T/Pump, USA) set at $37^{\circ} \mathrm{C}$. Local anesthetic (lidocaine $1 \%$ ) was applied to all skin incisions and pressure points. An incision was made exposing the skull, and small holes were drilled in the skull. Tungsten macroelectrodes (<1 M $\Omega$ World Precision Instruments, USA) were used to record the local field potential and the evoked potential in the PeF (coordinates from Bregma: A, -1.95; L, 1 and depth, 4.0 - 4.5mm).

Recordings were filtered $(0.3-50 \mathrm{~Hz})$ and amplified via an AC preamplifier (DAM80; World Precision Instruments). To elicit evoked potentials, the LC was stimulated using $120 \mu \mathrm{m}$ diameter stainless steel bipolar electrodes (World Precision Instruments, coordinates from Bregma: A, -5.4; L, 1 and depth, 4.0 - 4.5mm). Electrical 
stimulation was carried out with single square pulses $(0.3 \mathrm{~ms}$ duration and $20-50 \mu \mathrm{A}$ intensity, delivered at $1 \mathrm{~Hz}$; Cibertec stimulator, Spain). After a basal recording, IGF-I was injected either locally (young=13, old=13), or systemically (young=9, old=7). Both sexes were included.

For recordings in freely moving animals, mice were anesthetized as indicated above and placed in a stereotaxic device. The skin was cut along the midline, and a craniotomy was made $(0.5 \mathrm{~mm}$ diameter $)$ in the primary somatosensory area (S1). A stainless-steel macro-electrode of $<0.5 \mathrm{M} \Omega$ was placed without disrupting the meninges to register the cortical electrical activity (ECoG), using a DSI Implantable Telemetry device (Data Sciences International, USA). After surgery, mice remain in their cages for a minimum of 4 days to recover.

ECoG recordings were performed for 15 minutes from ZT1-ZT19, every 2 hours. Signals were stored in a computer using DSI software and filtered off-line between 0.3$50 \mathrm{~Hz}$ with Spike 2 software. ECoG segments of 5 minutes were analyzed using the Fast Fourier Transform algorithm to obtain the power spectra. The mean power density was calculated for five different frequency bands that constitute the global ECoG: delta $(0.3-5 \mathrm{~Hz})$, theta $(5-8 \mathrm{~Hz})$, alpha $(8-12 \mathrm{~Hz})$, beta $(12-30 \mathrm{~Hz})$, and gamma bands $(30-50$ $\mathrm{Hz}$ ). The total power of the five frequency bands was considered $100 \%$, and the percentage of each frequency band was calculated for the 15 minutes in each time point. We used eight young and four old mice to determine the ECoG profile during the active and passive phases.

To assess sleep onset-latency, segments of $30 \mathrm{sec}$ of the ECoG recording were analyzed according to the presence of slow waves $(0.3-5 \mathrm{~Hz})$, fast waves $(>12 \mathrm{~Hz})$, and mouse movements. We measured the latency to sleep onset from the time the animal was placed on the platform until the absence of movement and the appearance of delta waves. ECoG recordings were performed at different time points through a remote computer.

\section{Data Analysis}

Evoked potentials elicited by LC electrical stimulation $(20-50 \mu \mathrm{A} ; 0.3 \mathrm{~ms}$ duration; at $1 \mathrm{~Hz}$ ) were calculated. The peak latency was calculated as time elapsed between the stimulus onset and the peak of the second evoked potential wave (orthodromic response, with a latency of $3.5 \pm 0.81 \mathrm{~ms}$ ). To quantify the orthodromic response, the area under the positive wave curve was measured from the beginning of the positive slope. The unit activity plots show the percentage of variation over the basal period ( 5 mins). 
Outliers and recordings that did not elicit at least $70 \%$ of increment activity were removed from the analysis to minimize interference from non-LH neurons.

\section{Immunoassays}

Immunocytochemistry. Animals were deeply anesthetized with pentobarbital (50 mg/kg) and perfused transcardially with $0.9 \%$ saline and then $4 \%$ paraformaldehyde in $0.1 \mathrm{M}$ phosphate buffer, $\mathrm{pH} 7.4$ (PB). Coronal 50- $\mu$ m-thick brain sections were cut in a vibratome and collected in PB $0.1 \mathrm{~N}$. Sections were incubated in permeabilization solution (PB $0.1 \mathrm{~N}, 1 \%$ Triton $\mathrm{X}-100$ ), followed by 48 hours incubation at $4{ }^{\circ} \mathrm{C}$ with primary antibody (1:500) in blocking solution (PB 0.1N, 0.1\% Triton X-100, 10\% normal horse serum). After washing three times in $0.1 \mathrm{~PB}$, Alexa-coupled mouse/rabbit polyclonal secondary antibodies (1:1000, Molecular Probes, USA) were used. Finally, a 1:1000 dilution in PB of Hoechst 33342 was added for 3 minutes. Slices were rinsed several times in $\mathrm{PB}$, mounted with gerbatol mounting medium, and allowed to dry. The omission of the primary antibody was used as a control.

Western Blotting. Assays were performed as described in detail elsewhere ${ }^{46}$. Densitometry analysis of blots was performed using the Odyssey system (Lycor Biosciences, USA). A representative blot is shown from a total of at least three independent experiments.

\section{Cell Image Analysis}

Confocal analysis was performed in a Leica (Germany) microscope. For doublestained orexin/c-fos cell counting, four sections per animal were scored using the Imaris software, as described ${ }^{6}$. Alternatively, for double labelled IGF-IR/orexin cells, confocal images were segmented via k-means clustering with the number of clusters set to 5 $(k=5)$ using MATLAB ${ }^{47}$ to obtain binary masks for each channel dividing background from foreground. Red channel masks (Orexin antibody) were further processed by individualizing unconnected regions, putative neurons, and eliminating isolated components with areas smaller than $25 \mu \mathrm{m}^{2}$. The number of neurons in each mask was manually assessed. Green channel masks (IGF-IR antibody) were also visually inspected to ensure proper segmentation. Red and green channels were superposed to study the area of co-localization. For each segmented neuron (red channel), the fraction of its area that co-localized with IGF-IR antibody (green channel) was measured as an indirect quantification of the amount of receptor present in that neuron. We referred to this fraction as the co-localization index. The co-localization index of each image was computed as the mean co-localization index of the neurons 
present in that image. Lastly, the final co-localization index for each condition was computed as the mean co-localization index of all the images belonging to that condition.

Images with only secondary antibody stainings were used to check specificity of the secondary antibody ${ }^{48}$ and segmented as described above. Specificity was evaluated by measuring the segmented receptor's area and the number of segmented neurons and comparing the results with tissue images that underwent a complete immunohistochemistry protocol.

\section{Astrocyte cultures}

Astroglial cultures were prepared as described in detail elsewhere ${ }^{49}$ from postnatal (day 1-2) brains. After the forebrain was removed and mechanically dissociated, the mixed cell suspension was centrifuged and plated in DMEM/F-12 (Life Technologies) with $10 \%$ fetal bovine serum (Life Technologies) and $100 \mathrm{mg} / \mathrm{ml}$ of antibioticantimycotic solution (Sigma-Aldrich, Spain). Cells were maintained for 2 weeks at $37^{\circ} \mathrm{C}, 5 \% \mathrm{CO}_{2}$ and re-plated at $10^{5}$ cells $/ \mathrm{cm}^{2}$ in a 12-multiwell plate and grown until $80 \%$ confluency. On the day of the experiment, cells were washed twice with warm PBS and medium without FCS was added. Then, LPS was added $(1 \mu \mathrm{g} / \mathrm{ml})$ and cells incubated for $12 \mathrm{~h}$ at $37^{\circ} \mathrm{C}$. After LPS treatment, cells were washed twice with PBS, and a fresh medium without FCS was added. AIKa305 was added (27nM) in DMSO for 3 hours at $37^{\circ} \mathrm{C}$. Controls received DMSO alone. After AIK treatment, IGF-I ( $\left.1 \mathrm{nM}\right)$ was added, and cells incubated for $1 \mathrm{~h}$ at $37^{\circ} \mathrm{C}$. Then, plates were placed on ice for 5 minutes, washed and $100 \mu \mathrm{l}$ of Lysis buffer containing proteases and phosphates inhibitors (Merck) with Laemmli loading buffer 1X, was added and cells scrapped on ice. Samples were frozen at $-20^{\circ} \mathrm{C}$ until use.

\section{Statistical Analysis}

Statistical analysis was performed using GraphPad Prism 6 software (San Diego, CA, USA) and R Package (Vienna, Austria). Depending on the number of independent variables, normally distributed data (Kolmogorov-Smirnov normality test), and the experimental groups compared, we used either Student's t-test, two-way ANOVAs, or Two-way repeated measure ANOVA, followed by Sidak's multiple comparison test. For non-normally distributed data, we used the Mann-Whitney U test to compare two groups, Kruskal-Wallis or Friedman test, with Dunn's multiple comparisons. As a post hoc analysis we used the Scheirer-Ray Test, a non-parametric alternative to multifactorial ANOVA. The sample size for each experiment was chosen based on previous 
experience and aimed to detect at least a $\mathrm{p}<0.05$ in the different tests applied, considering a reduced use of animals. Results are shown as mean \pm standard error (SEM) and $p$ values coded as follows: $* \mathrm{p}<0.05, * * \mathrm{p}<0.01, * * * \mathrm{p}<0.001$. Animals were included in each experimental group randomly by the researcher.

\section{Acknowledgments}

This work was funded by a grant from Ciberned and SAF2016-76462 (AEI/FEDER; MINECO). J.A. Zegarra-Valdivia acknowledges the financial support of the National Council of Science, Technology and Technological Innovation (CONCYTEC, Perú) through the National Fund for Scientific and Technological Development (FONDECYT, Perú). J. Fernandes received a post-doc fellowship from Fundação de Amparo à Pesquisa do Estado de São Paulo (FAPESP: \# 2017/14742-0; \# 2019/033685). Kentaro Suda is supported by Kobe University. We are thankful to M. Garcia for technical support.

\section{Author Contributions}

JAZV conducted experiments, prepared figures, results and wrote part of the manuscript. JF, ATS, MEFS, JP, AMF conducted experiments and prepared figures. KS and LMR conducted experiments, MN provided experimental expertise, JE analyzed data, MV provided reagents and data on AIK3a305, AN designed and conducted experiments and wrote part of the manuscript, ITA designed the study and wrote the manuscript.

\section{Competing interests}

MV and ITA have shares in Allinky BioPharma that provided AIK3a305. 


\section{LEGENDS TO FIGURES}

Figure 1: Altered sleep structure in old mice. A, Diagram of the intracranial localization of the electrodes in S1cortex; left hemisphere has the reference electrode in all cases. B-F, Sleep architecture during the light and dark period (ZT 1-19) determined by $\delta(\mathrm{C}), \theta(\mathrm{D}), \alpha(\mathrm{E}), \beta(\mathrm{F})$, and $\gamma(\mathrm{G})$ activity patterns in old (red line) and young mice (blue line). Old mice display lower delta activity, as compared to young ones, and an increase in fast-wave activity (young=8, old=4; male mice only, Two-Way ANOVA, and Sidak's multiple comparison test; $\left.{ }^{*} \mathrm{p}<0.05, * * \mathrm{p}<0.01, * * * \mathrm{p}<0.001\right)$. G, Average changes in ECoG bands during the passive phase (ZT 9 - 11) display significant differences in $\delta$ band $(* * * p<0.0004$, young $=13$, old $=8$, sex balanced, Two-Way ANOVA, and Sidak's multiple comparison test). H, latency to sleep-onset was markedly reduced in old mice $(* * \mathrm{p}<0.0099$, young $=11$, old $=8$, sex balanced, Unpaired t-test, and Welch's correction).

Figure 2: Loss of sensitivity to systemic IGF-I in aged mice. A, Average changes in ECoG bands from 20 to 60 min after administering IGF-I $(1 \mu \mathrm{g} / \mathrm{kg}$, ip) were compared with average baseline changes. ECoG response to IGF-I is lost in old mice $(n=7)$ in all bands, particularly in $\alpha, \delta$ and $\theta$ compared to young mice $(n=10) . * p<0.05$; $* * p<0.01$; $* * * \mathrm{p}<0.001$, One-Way ANOVA). B, IGF-I administered to anesthetized old mice produced an attenuated increase in $\alpha, \beta$ and $\theta$ band frequencies in the ECoG (compare to Figure 2 in Trueba et al 2013). C-F, Representative photomicrographs of c-fos ${ }^{+} /$orexin $^{+}$ cells immunostainings in young and old mice under saline and IGF-I condition. G, While young mice show increased c-fos expression in orexin neurons after ip IGF-I $(n=6, * * p<0.01)$, old mice show a not significant decreased expression $(n=6, p=0.4948)$. Note that old mice $(n=6)$ treated with saline show higher activation of $c$-fos than young saline mice $(\mathrm{n}=6, * * * \mathrm{p}<0.001$; sex balanced, Two-Way ANOVA, and Sidak's multiple comparison test).

Figure 3: Orexin neurons in the lateral hypothalamus lose sensitivity to IGF-I in old mice. A, Diagram of the experimental design. A stimulating electrode was placed in the $\mathrm{LC}$ and a recording electrode in the PeF at the lateral hypothalamus ( $\mathrm{LH})$. B, Young, but not old mice responded to local IGF-I application in the PeF (arrow, $10 \mu \mathrm{M}, 0.1 \mu \mathrm{l}$ ) after LC stimulation. Time course showing the evoked potential of orthodromic impulses after electrical stimulation of the LC in both experimental groups expressed as a percentage of basal responses at time 0 (at $5 \mathrm{~min} * * \mathrm{p}<0.0053$; at $10 \mathrm{~min} * * * \mathrm{p}<0.001$, $15 \min * * * \mathrm{p}<0.001$, and $20 \min * * * \mathrm{p}<0.001 ; \mathrm{n}=13$ per group; sex balanced, Two-Way Repeated Measure ANOVA, Sidak's Multiple comparison test). C, Intraperitoneal injection of IGF-I (arrow, $1 \mu \mathrm{g} / \mathrm{g}$ ) increased neuronal activity in PeF orexin neurons after LC stimulation in young but not old mice $(* * * \mathrm{p}=0.0003$; young=9; old=7; sex balanced, Ordinary Two-Way ANOVA, Sidak's Multiple comparison test).

Figure 4: Increased expression of IGF-IR in orexin neurons of old mice. A, Representative photomicrograph of the mouse hypothalamus showing staining of orexin 
(red) and IGF-IR (green) in the PeF area of the lateral hypothalamus (LH). B, Colocalization ratio of IGF-1R/orexin cells in young and old mice $(* * * \mathrm{p}=0.0001$, young=32, old=26; male-only, Unpaired t-test, and Welch's correction). C, Mean orexin immunoreactivity per field in young and old mice, as detected by immunocytochemistry (young=32, old=26; $\mathrm{p}=0.8766$, Unpaired t-test).

Figure 5: IGF-IR sensitization with Aik3a305 recovers orexin responses to IGF-I and rejuvenates ECoG patterns in old mice. A, Representative photomicrograph of $\operatorname{orexin}^{+}$(red) and c-fos ${ }^{+}$(green) cells under saline and IGF-I condition in old AIK3treated mice. Scale bars: $100 \mu \mathrm{m}$. B, Counting of double-stained c-fos ${ }^{+} /$orexin $^{+}$cells after AIK 3 treatment of old mice shows a recovery of the c-fos response to IGF-I ( $n=3$ per group, ${ }^{* *} \mathrm{p}=0.0082$, sex balanced, Unpaired t-test, and Welch's correction). $\mathbf{C}$, Average ECoG bands during the passive phase (ZT 9 - 11) display significant differences in the $\delta$ band in old AIK3-treated mice, compared to old vehicle-injected mice $(* * \mathrm{p}=0.0085$, old AIK3 $=14$, old $=8$, sex balanced, Two-Way ANOVA, and Sidak's multiple comparison test). D, Treatment with AIK3 normalized sleep-onset latency (***p<0.001, $\mathrm{n}=7$ per group, Unpaired t-test, and Welch's correction). E, Old AIK3 mice recover responses to IGF-I in the $\mathrm{LH}$ after local application $(10 \mu \mathrm{M}, 0.1 \mu \mathrm{l})$ and LC stimulation. Time course showing the evoked potential of orthodromic impulses after electrical stimulation of the LC in both experimental groups expressed as a percentage of basal responses at time 0 (at $15 \mathrm{~min} * \mathrm{p}=0.0109$, and $20 \mathrm{~min} * * * \mathrm{p}=0.0004$; $\mathrm{n}=13$ per group; sex balanced, Two-Way Repeated Measure ANOVA, Sidak's Multiple comparison test).

Supplementary Figure 1: A, No differences were seen in the ECoG band analysis of young male and female mice ( $\leq 6$ months old). B, No significant differences were seen in the ECoG band analysis of old male and female mice ( $\geq 18$ months old). C, No differences were seen in the latency of the evoked potential registered in the PeF of young and old mice after stimulation of the LC. D, No differences between groups in the basal evoked potential in LH after LC stimulation (One-way ANOVA, p=0.1028).

Supplementary Figure 2: A, AIK3 sensitizes astrocytes to IGF-I. After treatment with LPS $(1 \mu \mathrm{g} / \mathrm{ml})$, astrocytes become unresponsive to IGF-I, as determined by lack of phosphorylated Akt (pAkt) after 0.1 or $1 \mathrm{nM}$ IGF-I. Astrocytes simultaneously receiving AIK3a305 (27 $\mathrm{mM}$ ) regain sensitivity to IGF-I, as phosphorylated Akt was readily detected. A representative blot is shown. $\mathbf{B}$, Concentration along time in the blood (blue trace) and brain (red trace) after oral administration of AIK3a305 (10 $\mathrm{mg} / \mathrm{kg}$ ) in adult male mice (Swiss albino). C, No differences were seen in the ECoG band analysis of young mice ( $\leq 6$ months old), old mice ( $\geq 18$ months old), and old mice treated with AIK3. D, No differences between groups in the basal evoked potential in LH after LC. 


\section{References}

1 Mander, B. A., Winer, J. R. \& Walker, M. P. Sleep and Human Aging. Neuron 94, 19-36, (2017).

2 Ju, Y. E., Lucey, B. P. \& Holtzman, D. M. Sleep and Alzheimer disease pathology--a bidirectional relationship. Nat Rev Neurol 10, 115-119, (2014).

3 Nixon, J. P. et al. Sleep disorders, obesity, and aging: the role of orexin. Ageing Res Rev 20, 63-73, (2015).

4 Kenyon, C. A conserved regulatory system for aging. Cell 105, 165-168 (2001).

5 Zegarra-Valdivia, J. A., Santi, A., Fernandez de Sevilla, M. E., Nunez, A. \& Torres Aleman, I. Serum Insulin-Like Growth Factor I Deficiency Associates to Alzheimer's Disease Co-Morbidities. J Alzheimers Dis 69, 979-987, (2019). Zegarra-Valdivia, J. A. et al. Insulin-like growth factor I modulates sleep through hypothalamic orexin neurons. FASEB J 34, 15975-15990, (2020).

7 Sakurai, T. The neural circuit of orexin (hypocretin): maintaining sleep and wakefulness. Nat Rev Neurosci 8, 171-181 (2007).

8 Junnila, R. K., List, E. O., Berryman, D. E., Murrey, J. W. \& Kopchick, J. J. The GH/IGF-1 axis in ageing and longevity. Nat Rev Endocrinol (2013).

9 Cohen, E. \& Dillin, A. The insulin paradox: aging, proteotoxicity and neurodegeneration. Nat Rev. Neurosci 9, 759-767 (2008).

10 Mattson, M. P., Maudsley, S. \& Martin, B. A neural signaling triumvirate that influences ageing and age-related disease: insulin/IGF-1, BDNF and serotonin. Ageing Res. Rev 3, 445-464 (2004).

11 Muller, A. P. et al. Reduced brain insulin-like growth factor I function during aging. Mol Cell Neurosci 49, 9-12 (2012).

12 Ashpole, N. M., Sanders, J. E., Hodges, E. L., Yan, H. \& Sonntag, W. E. Growth hormone, insulin-like growth factor-1 and the aging brain. Experimental Gerontology 68, 76-81, (2015).

13 Lai, M., Hibberd, C. J., Gluckman, P. D. \& Seckl, J. R. Reduced expression of insulin-like growth factor 1 messenger RNA in the hippocampus of aged rats. Neurosci. Lett 288, 66-70 (2000).

14 Palin, K. et al. Age-impaired fluid homeostasis depends on the balance of IL6/IGF-I in the rat supraoptic nuclei. Neurobiol. Aging 30, 1677-1692, (2008).

15 Bliwise, D. L. Sleep in normal aging and dementia. Sleep 16, 40-81 (1993).

16 Hasan, S., Dauvilliers, Y., Mongrain, V., Franken, P. \& Tafti, M. Age-related changes in sleep in inbred mice are genotype dependent. Neurobiology of Aging 33, 195.e113-195.e126, (2012).

17 Trueba-Saiz, A. et al. Loss of serum IGF-I input to the brain as an early biomarker of disease onset in Alzheimer mice. Transl Psychiatry 3, e330 (2013).

18 de Lecea, L. et al. The hypocretins: hypothalamus-specific peptides with neuroexcitatory activity. Proc Natl Acad Sci U S A 95, 322-327 (1998).

19 Carro, E., Trejo, J. L., Busiguina, S. \& Torres-Aleman, I. Circulating insulinlike growth factor I mediates the protective effects of physical exercise against brain insults of different etiology and anatomy. J. Neurosci 21, 5678-5684 (2001).

20 Nishijima, T. et al. Neuronal activity drives localized blood-brain-barrier transport of serum insulin-like growth factor-I into the CNS. Neuron 67, 834846 (2010).

21 Jain, S., Golde, D. W., Bailey, R. \& Geffner, M. E. Insulin-like growth factor-I resistance. Endocr. Rev 19, 625-646 (1998). 
22 Azpurua, J. et al. IGF1R levels in the brain negatively correlate with longevity in 16 rodent species. Aging (Albany. NY) 5, 304-314 (2013).

23 Stenvers, K. L., Lund, P. K. \& Gallagher, M. Increased expression of type 1 insulin-like growth factor receptor messenger RNA in rat hippocampal formation is associated with aging and behavioral impairment. Neuroscience $\mathbf{7 2}$, 505-518 (1996).

24 Ding, H., Gao, X. L., Hirschberg, R., Vadgama, J. V. \& Kopple, J. D. Impaired actions of insulin-like growth factor 1 on protein Synthesis and degradation in skeletal muscle of rats with chronic renal failure. Evidence for a postreceptor defect. J. Clin. Invest 97, 1064-1075 (1996).

25 Trueba-Saiz, A. et al. Circulating Insulin-like Growth Factor I Regulates Its Receptor in the Brain of Male Mice. Endocrinology 158, 349-357, (2017).

26 Martín-Segura, A. et al. Age-associated cholesterol reduction triggers brain insulin resistance by facilitating ligand-independent receptor activation and pathway desensitization. Aging Cell 18, e12932, (2019).

27 Kappeler, L. et al. Brain IGF-1 Receptors Control Mammalian Growth and Lifespan through a Neuroendocrine Mechanism. PLoS Biol 6, e254, (2008).

28 Kenyon, C., Chang, J., Gensch, E., Rudner, A. \& Tabtiang, R. A C. elegans mutant that lives twice as long as wild type. Nature 366, 461-464 (1993).

29 Laron, Z. Effects of growth hormone and insulin-like growth factor 1 deficiency on ageing and longevity. Novartis. Found. Symp 242, 125-137 (2002).

30 Mao, K. et al. Late-life targeting of the IGF-1 receptor improves healthspan and lifespan in female mice. Nat Commun 9, 2394, (2018).

31 Milman, S. et al. Low insulin-like growth factor-1 level predicts survival in humans with exceptional longevity. Aging Cell 13, 769-771, (2014).

32 Kawano, T., Nagatomo, R., Kimura, Y., Gengyo-Ando, K. \& Mitani, S. Disruption of ins-11, a Caenorhabditis elegans Insulin-Like Gene, and Phenotypic Analyses of the Gene-Disrupted Animal. Biosci. Biotechnol. Biochem 70, 3084-3087, (2006).

33 Marino, G. et al. Insulin-like growth factor 1 treatment extends longevity in a mouse model of human premature aging by restoring somatotroph axis function. Proc. Natl. Acad. Sci. U. S. A 107, 16268-16273 (2010).

34 Matsunaga, Y., Gengyo-Ando, K., Mitani, S., Iwasaki, T. \& Kawano, T. Physiological function, expression pattern, and transcriptional regulation of a Caenorhabditis elegans insulin-like peptide, INS-18. Biochem. Biophys. Res. Commun 423, 478-483 (2012).

35 Merry, T. L. et al. Impairment of insulin signalling in peripheral tissue fails to extend murine lifespan. Aging Cell, 16, 761-771, (2017).

36 Bai, H., Kang, P. \& Tatar, M. Drosophila insulin-like peptide-6 (dilp6) expression from fat body extends lifespan and represses secretion of Drosophila insulin-like peptide-2 from the brain. Aging Cell 11, 978-985 (2012).

37 Le, B. E. The somatotropic axis may not modulate ageing and longevity in humans. Biogerontology 17, 421-429, (2015).

38 Milman, S., Huffman, Derek M. \& Barzilai, N. The Somatotropic Axis in Human Aging: Framework for the Current State of Knowledge and Future Research. Cell Metabolism 23, 980-989, (2016).

39 Kauffman, A. L., Ashraf, J. M., Corces-Zimmerman, M. R., Landis, J. N. \& Murphy, C. T. Insulin signaling and dietary restriction differentially influence the decline of learning and memory with age. PLoS Biol 8, e1000372 (2010). 
40 Chaker, Z. et al. Hypothalamic neurogenesis persists in the aging brain and is controlled by energy-sensing IGF-I pathway. Neurobiol Aging 41, 64-72, (2016).

41 Landi, F. et al. Free insulin-like growth factor-I and cognitive function in older persons living in community. Growth Horm. IGF. Res 17, 58-66, (2007).

42 Lichtenwalner, R. J. et al. Intracerebroventricular infusion of insulin-like growth factor-I ameliorates the age-related decline in hippocampal neurogenesis. Neuroscience 107, 603-613 (2001).

43 Arwert, L. I. et al. Memory performance and the growth hormone/insulin-like growth factor axis in elderly: a positron emission tomography study. Neuroendocrinology 81, 31-40 (2005).

$44 \mathrm{Hu}$, A. et al. The effect of constitutive over-expression of insulin-like growth factor 1 on the cognitive function in aged mice. Brain Res 1631, 204-213, (2016).

45 Tanabe, K., Itoh, M. \& Tonoki, A. Age-Related Changes in Insulin-like Signaling Lead to Intermediate-Term Memory Impairment in Drosophila. Cell Rep 18, 1598-1605, (2017).

46 Fernandez, A. M. et al. Regulation of the phosphatase calcineurin by insulin-like growth factor I unveils a key role of astrocytes in Alzheimer's pathology. Mol Psychiatry 17, 705-718 (2012).

47 Dima, A. A. et al. Comparison of segmentation algorithms for fluorescence microscopy images of cells. Cytometry A 79, 545-559, (2011).

48 Burry, R. W. Controls for immunocytochemistry: an update. J Histochem Cytochem 59, 6-12, (2011).

49 Fernandez, A. M., Fernandez, S., Carrero, P., Garcia-Garcia, M. \& TorresAleman, I. Calcineurin in reactive astrocytes plays a key role in the interplay between proinflammatory and anti-inflammatory signals. J Neurosci $\mathbf{2 7}, 8745$ 8756 (2007). 
A

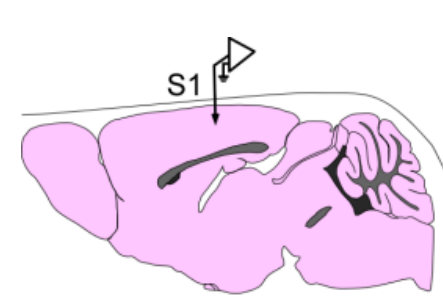

D

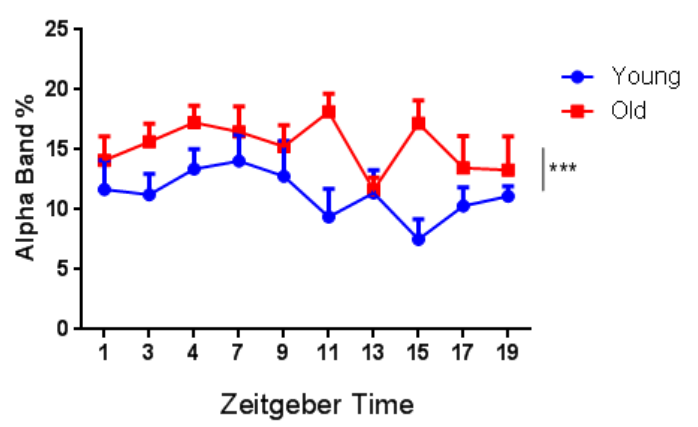

G
B

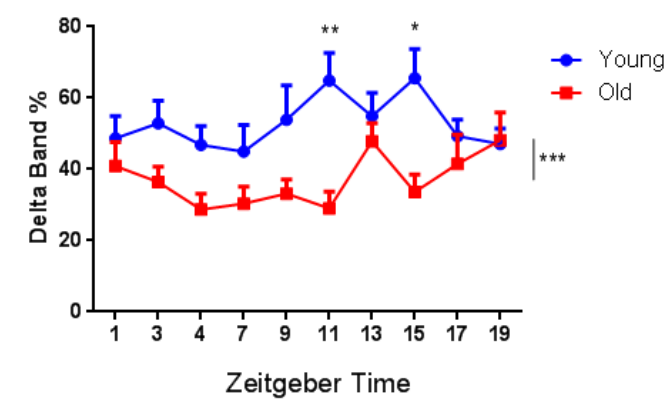

E

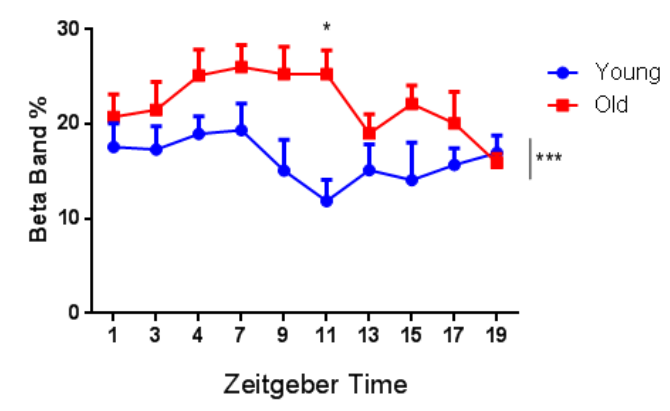

$\mathrm{H}$

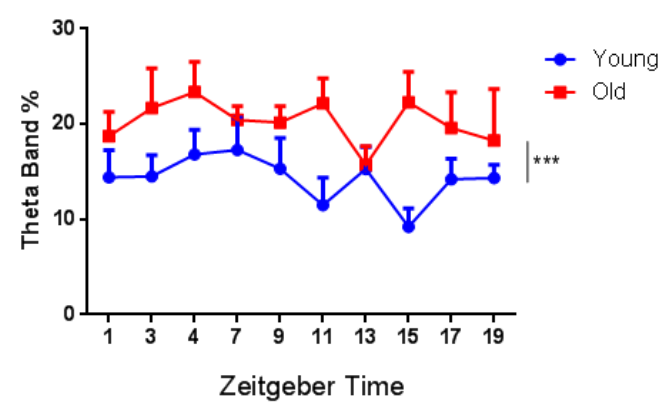

F

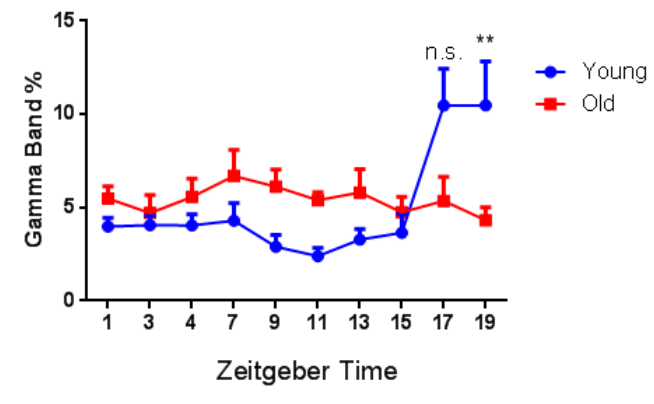

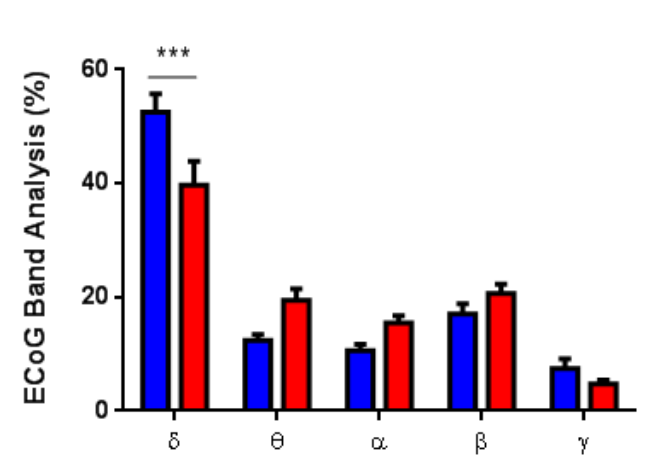

Young
Old

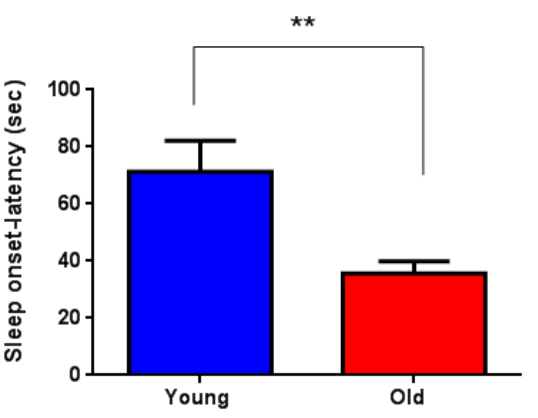

Figure 1 
A

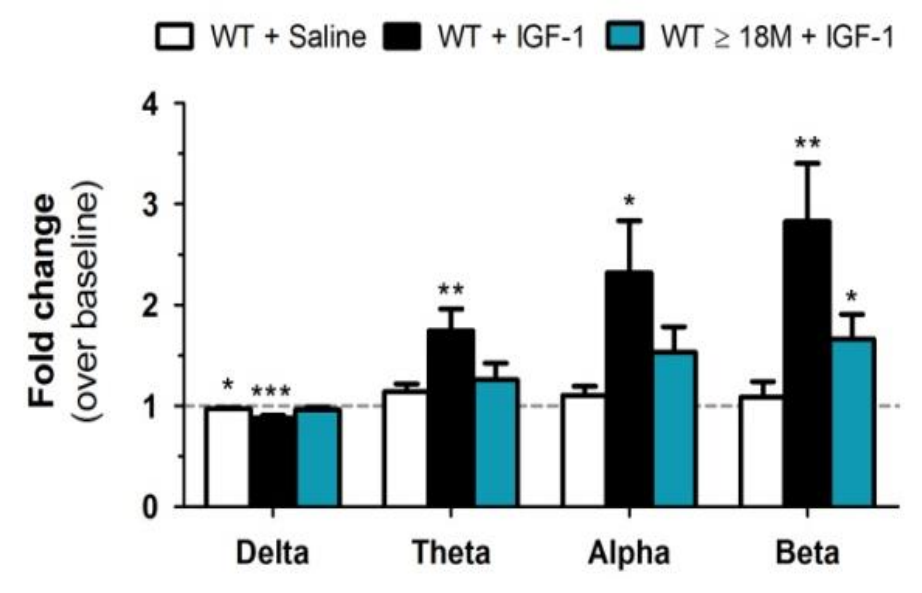

B

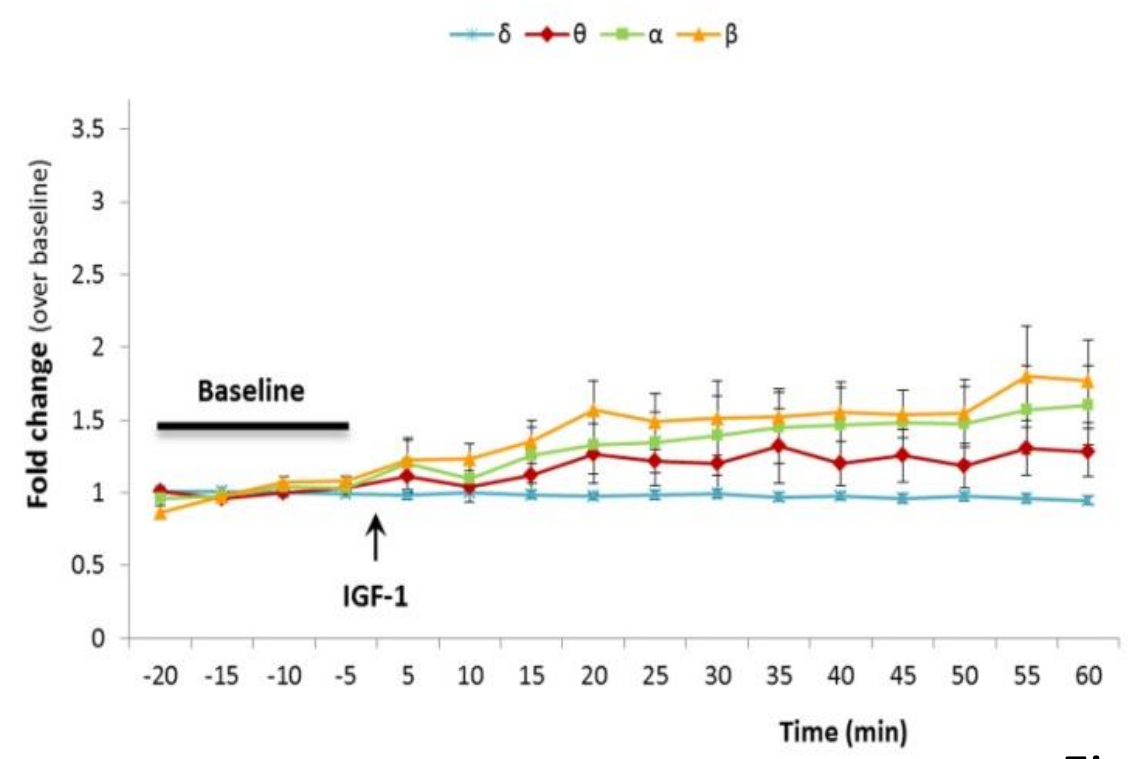

Figure 2
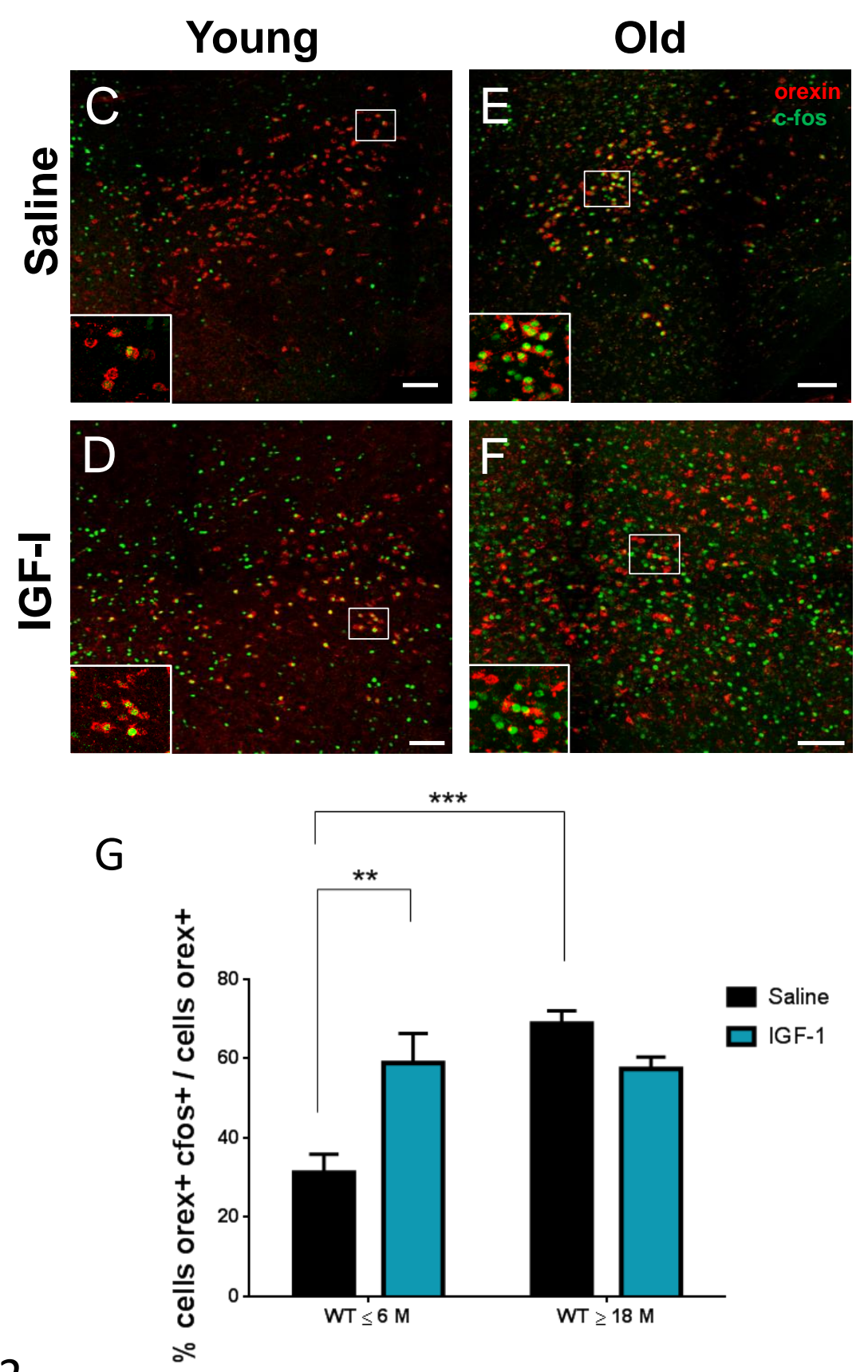
A

$$
\sqrt{1}
$$

B

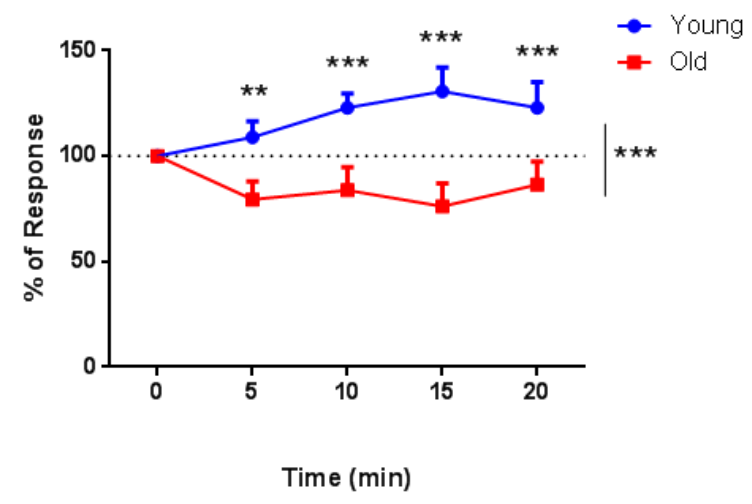

C

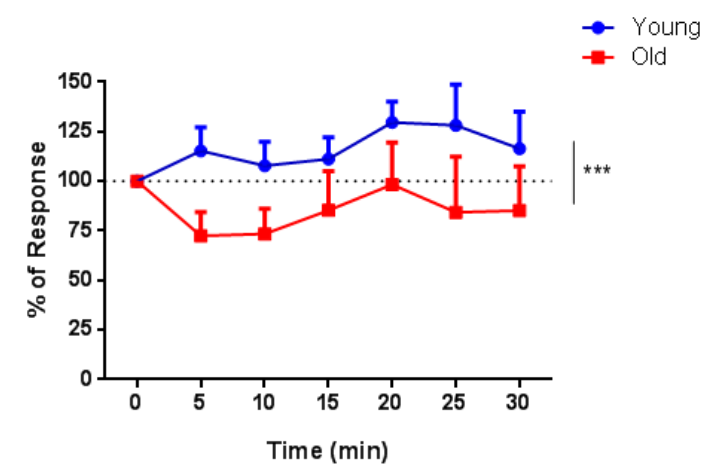

Figure 3 
A

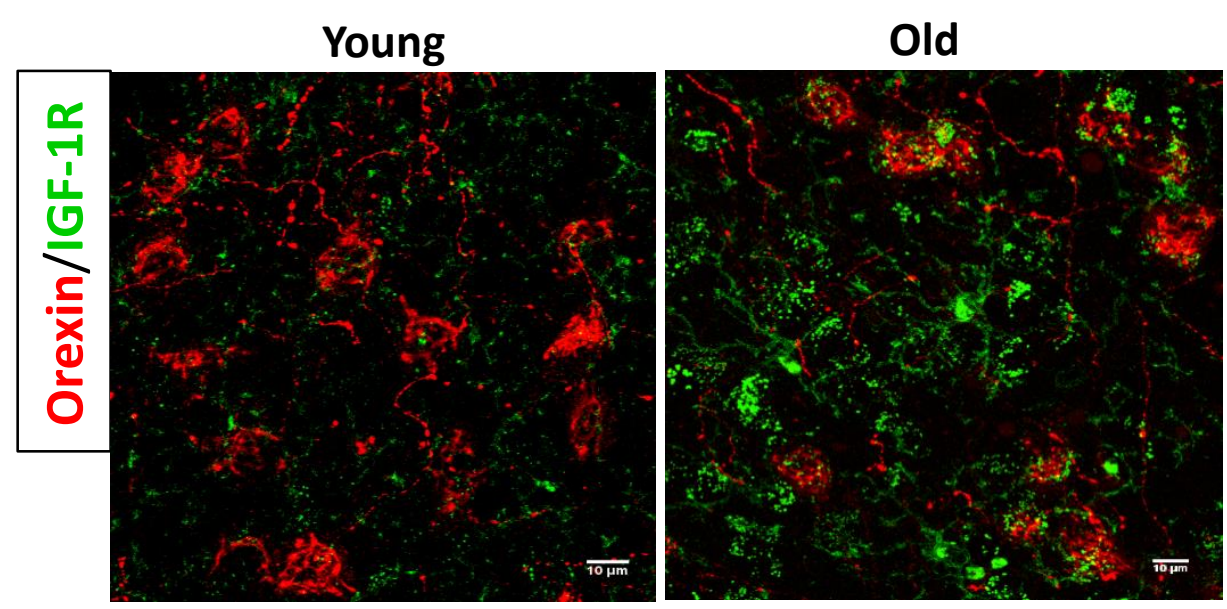

B

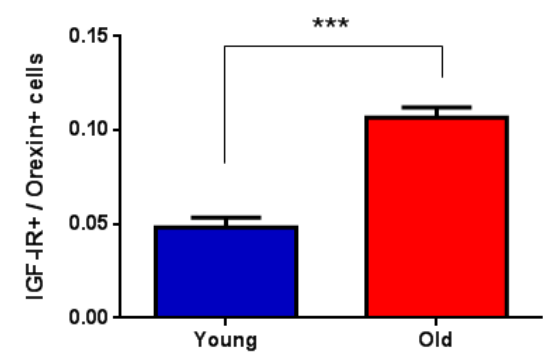

C

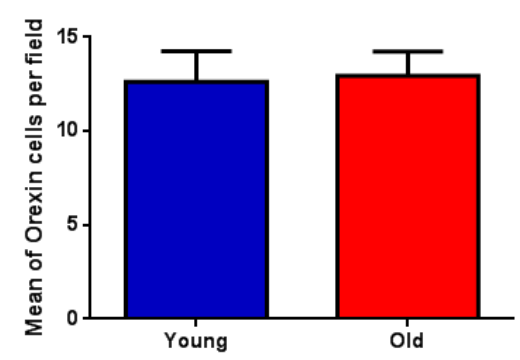

Figure 4 


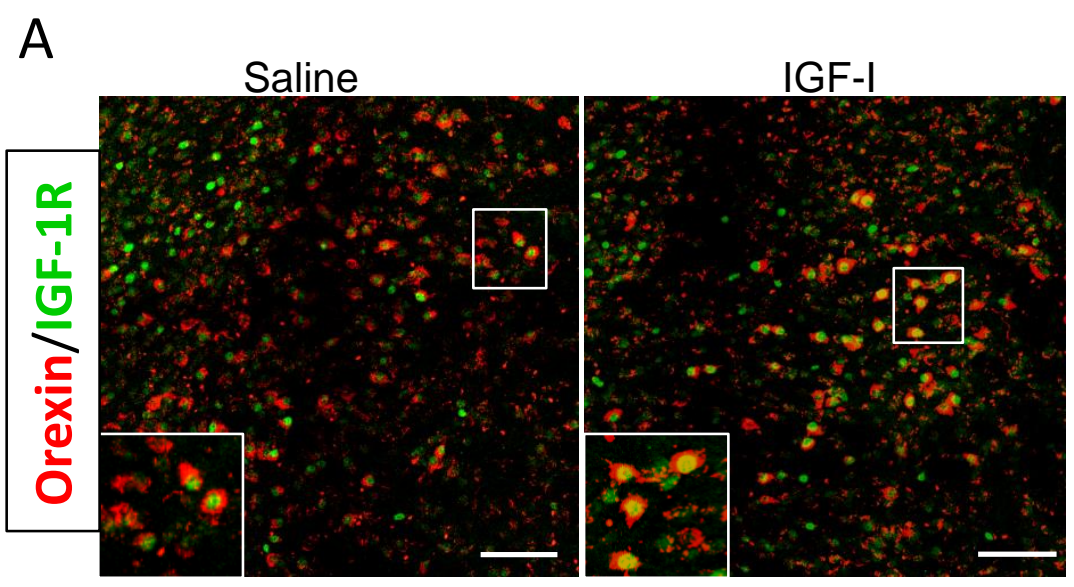

C

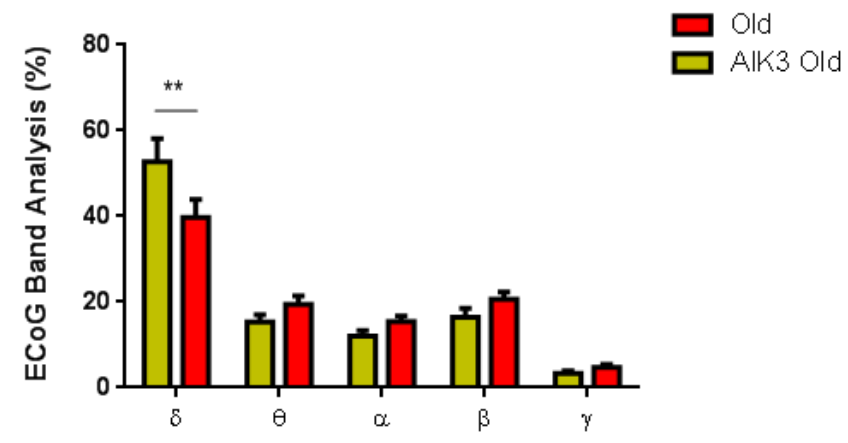

B
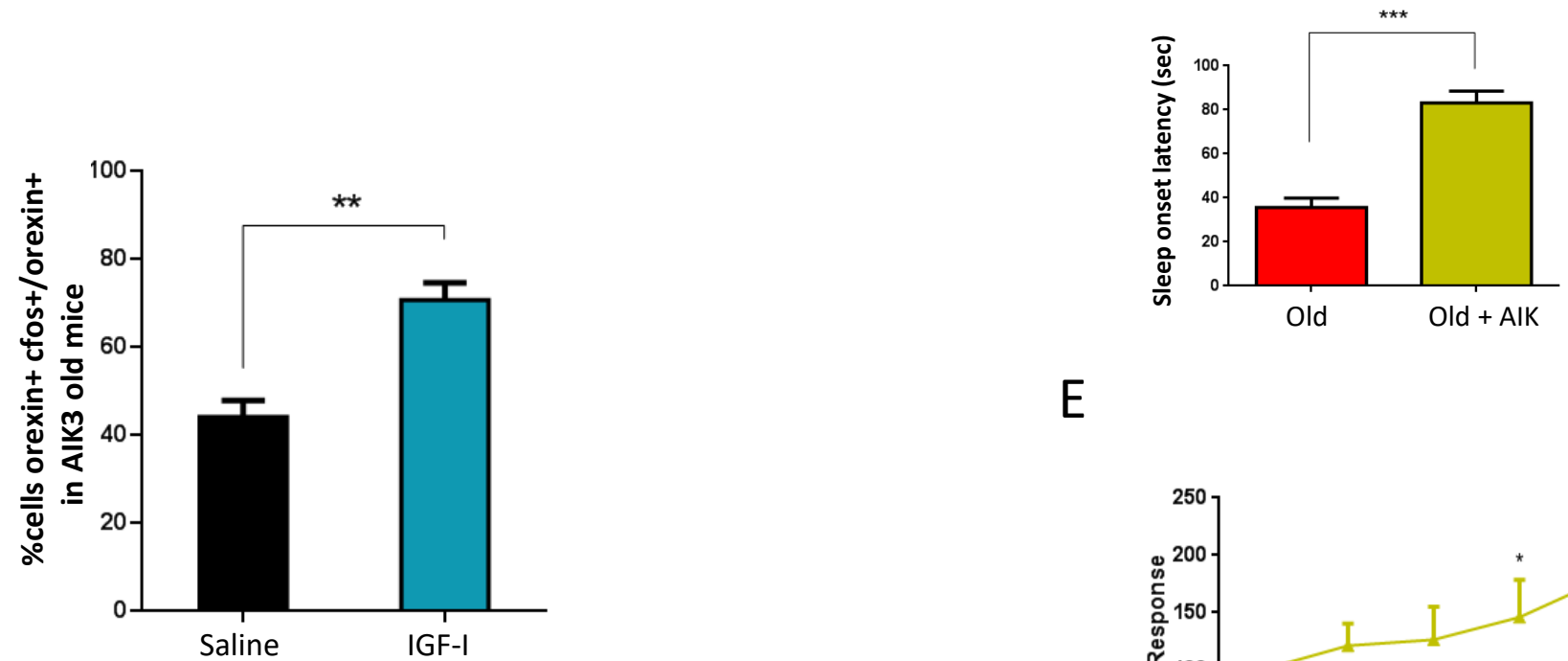

E

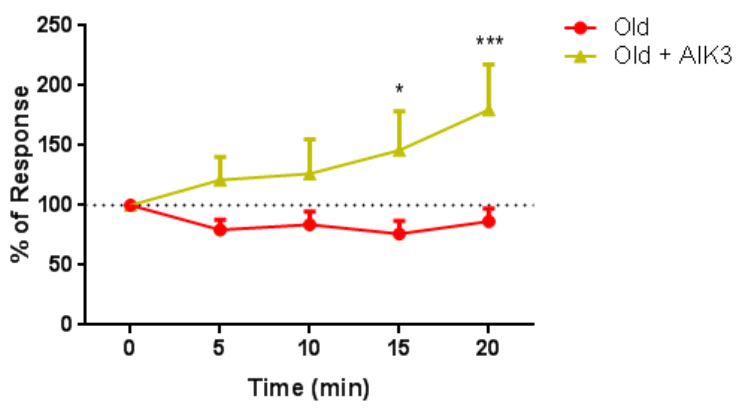

Figure 5 